\title{
geoquafiar
} Malaysian Journal of Society and Space

\section{Pentadbiran British di Sabah: Kesejahteraan Anak Negeri melalui penubuhan Mahkamah Anak Negeri 1884-1965}

\author{
Azlizan Mat Enh ${ }^{1}$, Salbiya Jamaluddin ${ }^{1}$ \\ ${ }^{1}$ Pusat Kajian Sejarah, Politik dan Hal Ehwal Antarabangsa, Fakulti Sains Sosial dan Kemanusiaan, \\ Universiti Kebangsaan Malaysia
}

Correspondence: Azlizan Mat Enh (azlizan@ukm.edu.my)

Received: 14 June 2019; Accepted: 25 February 2020; Published: 27 February 2020

\begin{abstract}
Abstrak
Undang-undang adat istiadat di Sabah memainkan peranan yang penting dalam mengatur cara hidup masyarakat anak negeri yang terdiri daripada pelbagai suku dan budaya. Justeru, pentadbiran Syarikat Borneo Utara British (BNBCC) di Sabah tidak campur tangan dalam urusan hukum adat masyarakat tempatan. Oleh itu, bagi menjamin kebajikan dan keistimewaan masyarakat anak negeri Sabah, Mahkamah Anak Negeri telah ditubuhkan bagi mengendalikan hal ehwal anak negeri Sabah dari aspek perundangan adat. Artikel ini akan menganalisis kepentingan yang membawa kepada faktorfaktor utama penubuhan Mahkamah Anak Negeri ini kepada anak negeri Sabah. Kajian ini menggunakan kaedah analisis kandungan. Melalui kaedah ini, data-data yang diperolehi untuk menghasilkan artikel ini adalah daripada sumber-sumber pertama yang terdapat di Arkib Negeri Sabah dan dokumen-dokumen Mahkamah Anak Negeri. Hasil dapatan kajian ini mendapati penubuhan Mahkamah Anak Negeri adalah disebabkan beberapa faktor iaitu pengaruh undangundang adat, menjimatkan kos pentadbiran BNBCC, Piagam Diraja 1881 serta pertambahan populasi penduduk.
\end{abstract}

Kata kunci: adat, mahkamah anak negeri, masyarakat, Sabah, suku, Syarikat Borneo Utara British (BNBCC)

\section{British administration in Sabah: Well-being of Anak Negeri through the establishment of The Native Court 1884-1965}

\begin{abstract}
Customary laws in Sabah play an important role in regulating the way of life of indigenous peoples of various ethnicities and cultures. Therefore, the administration of the British North Borneo Company (BNBCC) in Sabah did not interfere in the customary law of the local community. Therefore, to safeguard the welfare and privileges of Sabah's indigenous peoples, the Native Court has been established to deal with the affairs of the indigenous people of Sabah in terms of customary law. This article will analyze the reasons that lead to the establishment of this Native Court for the native of Sabah. This study uses content analysis method. Through this method, the data obtained to produce this article are from the primary sources available in the Sabah State Archives and Native Court documents. The findings of this study found that the formation of the Native Courts was due to
\end{abstract}


several factors, namely the influence of customary law, saving the administration costs of the BNBCC, the Royal Charter 1881 and the increase in population.

Keywords: custom, Native Court, society, Sabah, tribes, British North Borneo Company (BNBCC)

\section{Pengenalan}

Mahkamah Anak Negeri ditubuhkan dalam setiap daerah di negeri Sabah. Mahkamah Anak Negeri pertama ditubuhkan di Sabah adalah pada tahun 1884 di Putatan (Sabihah, 1985). BNBCC merupakan kuasa yang bertanggungjawab membawa kepada penubuhan Mahkamah Anak Negeri di Sabah dan memformalisasikan institusi ini sebagai badan kehakiman yang rasmi pada tahun 1913 (NBCA 806, 1913). BNBCC telah memformalisasikan beberapa aspek dalam sistem undang-undang tradisional yang sedia ada. BNBCC memperbaharui undang-undang ini agar dapat menjadikan undang-undang adat sebagai satu aturan yang bersistem (Sharifah Zaleha Syed Hassan, 1995). Fungsi Mahkamah Anak Negeri dalam mengadili kes-kes anak negeri Sabah terhenti sementara semasa pendudukan Jepun pada 1942-1945. Apabila Sabah dijadikan tanah jajahan Kerajaan British (1946-1963), peranan Mahkamah Anak Negeri telah dikembalikan semula dan pentadbirannya semakin sistematik dengan penggubalan Ordinan Mahkamah Anak Negeri 1953. Begitu juga selepas Sabah mencapai kemerdekaan, Mahkamah Anak Negeri terus dikekalkan sebagai satu usaha Kerajaan Negeri Sabah menghormati dan menjaga undang-undang adat serta kebajikan anak negeri di Sabah.

Dalam konteks anak negeri Borneo Utara, sejarah mengenai undang-undang adat merupakan satu perkara penting bagi sejarah Borneo Utara. Sebelum Borneo Utara ditadbir oleh BNBCC pada tahun 1881, komuniti anak negeri di Borneo Utara telah mempunyai sistem perundangan mereka yang tersendiri iaitu berlandaskan kepada undang-undang adat yang diwarisi sejak turun-temurun. Malahan, mereka juga telah mempunyai sistem kehakiman yang tersendiri menyerupai Mahkamah Anak Negeri. Sistem kehakiman tersebut merupakan mahkamah tradisional yang berpandukan kepada undang-undang adat dan diketuai oleh Orang Tua (Ketua Kampung). Walau bagaimanapun, pentadbiran mahkamah tradisional pada waktu berkenaan dijalankan dalam bentuk tidak formal. Undang-undang adat suku kaum mereka diperolehi secara lisan yang diperturunkan sejak nenek moyang lagi. Hal ini memperlihatkan bahawa undang-undang adat yang diamalkan oleh anak negeri Borneo Utara adalah lebih sesuai untuk dipraktikkan di dalam sistem keadilan mereka. Justeru, terdapat pelbagai faktor yang menyumbang kepada penubuhan Mahkamah Anak Negeri Sabah.

\section{Kajian literatur}

Berdasarkan kepada hasil pemerhatian pengkaji, tidak banyak kajian yang dilakukan berkenaan Mahkamah Anak Negeri di Sabah. Kajian-Kajian terdahulu hanya membuat perbincangan mengenai Mahkamah Anak Negeri Sabah secara ringkas dan tidak dilakukan secara mendalam. Ranjit Singh (2000) menyentuh mengenai pentadbiran BNBCC dan juga masyarakat anak negeri di Sabah pada tahun 1865-1941. Perihal Mahkamah Anak Negeri Sabah tidak banyak dikupas dalam karya ini. Beliau mengaitkan institusi pentadbiran tempatan yang diketuai oleh Ketua Anak Negeri dan Orang Tua kampong dalam pentadbiran Mahkamah Anak Negeri di Sabah. Semasa zaman pemerintahan BNBCC, Mahkamah Anak Negeri diketuai oleh Ketua Anak Negeri dan dibantu oleh Orang Tua dalam mengendalikan 
hal ehwal undang-undang adat anak negeri Sabah. Kajian ini amat berguna dalam mengkaji pentadbiran Mahkamah Anak Negeri semasa era BNBCC.

Karya Evans (1967) diterbitkan bagi tujuan memberi panduan dalam pentadbiran Mahkamah Anak Negeri di Sabah pada peringkat awal kemerdekaan Sabah. Karya ini menerangkan mengenai bidang kuasa, pengendalian prosiding kes di Mahkamah Anak Negeri yang merangkumi beberapa aspek penting seperti bukti, saksi, sumpah, penghakiman, rekod dan rayuan. Walaupun risalah ini tidak lengkap dan berupa gambaran asas, namun karya ini berguna untuk kajian pengkaji sebagai rujukan asas untuk mendalami perihal panduan dan tatacara dalam sesuatu perbicaraan kes dalam Mahkamah Anak Negeri Sabah. Karya Phelan (2003) merangkumi aspek berkenaan pentadbiran Mahkamah Anak Negeri Sabah, pentadbiran undang-undang adat negeri Sabah dan masa depan undang-undang adat. Kajian ini menyingkap proses pentadbiran undang-undang adat anak negeri di Sabah dengan memaparkan kes-kes yang dibicarakan di Mahkamah Anak Negeri Sabah. Kekuatan kajian ini ialah kupasan mengenai latar belakang, bidang kuasa, undang-undang, amalan dan tatacara Mahkamah Anak Negeri di samping kepentingan undang-undang adat anak negeri Sabah adalah lebih jelas.

Sabihah Osman (1985) membincangkan mengenai system politik Sabah dengan lebih mendalam semasa era pemerintahan BNBCC dan penyertaan Bumiputera ke dalam bidang politik di Sabah sepanjang tahun 1811 hingga tahun 1941. Walau bagaimanapun, karya beliau tidak banyak menimbulkan perbincangan mengenai Mahkamah Anak Negeri di Sabah. Namun demikian, karya beliau memberi gambaran awal mengenai institusi perundangan tempatan terutama sejarah awal Mahkamah Anak Negeri semasa era pemerintahan BNBCC di Sabah. Sementara Mosli Tarsat (2007) memberi maklumat yang jelas mengenai jawatan Ketua Anak Negeri dalam pentadbiran Mahkamah Anak Negeri Sabah pada tahun 1946 hingga tahun 1990. Kajian ini penting kerana menyentuh mengenai undang-undang Mahkamah Anak Negeri Sabah seperti Ordinan Pentadbiran Kampung 1913, Ordinan Pentadbiran Anak Negeri 1937, Ordinan Mahkamah Anak Negeri 1953 sehinggalah digantikan dengan Enakmen Mahkamah Anak Negeri 1992.

\section{Kaedah dan kawasan kajian}

Kaedah kajian adalah menggunakan kaedah kualitatif iaitu analisis ke atas sumber-sumber primer dan sekunder. Sumber primer sebagai sumber utama yang mempunyai peranan penting dalam penyelidikan sejarah. Kaedah kualitatif termasuk menggunakan pendekatan kajian kepustakaan. Kajian kepustakaan ini meliputi penilitian dan penafsiran terhadap sumber-sumber. Sumber primer adalah berdasarkan rekod-rekod kerajaan yang telah diterbitkan mahupun tidak diterbitkan. Antara sumber-sumber primer yang digunakan ialah laporan tahunan, ordinan, enakmen, akta, minit mesyuarat, data dalam mikrofilem, akhbar dan sebagainya. Diikuti pula dengan sumber sekunder yang digunakan untuk menyokong data-data sumber primer. Sumber sekunder didapati daripada buku, jurnal, artikel, tesis, laporan dan sebagainya. Proses penyelidikan sejarah juga membabitkan penyusunan secara sistematik dan penilaian terhadap maklumat-maklumat yang berkaitan dengan peristiwa yang berlaku.

Kawasan kajian yang dipilih adalah negeri Sabah dengan memfokuskan kepada perbicangan mengenai institusi Mahkamah Anak Negeri Sabah. Lokasi kajian tidak terhad kepada kawasan bandar atau luar bandar sahaja tetapi merangkumi keseluruhan kawasan negeri Sabah. Pengkaji memilih negeri Sabah sebagai kawasan kajian kerana Mahkamah Anak Negeri hanya wujud di dua buah negeri sahaja iaitu Sabah dan Sarawak. Malahan, Mahkamah Anak Negeri ini begitu istimewa dan popular dalam kalangan anak negeri Sabah. 
Institusi ini mempunyai peranan yang begitu signifikan sebagai badan kehakiman khas untuk anak negeri Sabah dan memartabatkan undang-undang adat tempatan. Justeru, kerajaan telah memberikan tumpuan kepada pemantapan dan pemerkasaan Mahkamah Anak Negeri Sabah agar terus relevan untuk dikekalkan sebagai badan kehakiman negeri Sabah.

\section{Hasil kajian dan perbincangan}

\section{Pengaruh Undang-Undang Adat}

Pengaruh undang-undang adat merupakan antara faktor utama yang membawa kepada penubuhan Mahkamah Anak Negeri di Borneo Utara atau Sabah. Hukum adat yang diamalkan oleh komuniti anak negeri Borneo Utara ini dikenali sebagai undang-undang adat. Undang-undang adat berperanan penting dan mempunyai pengaruh yang besar kepada setiap suku kaum anak negeri di Borneo Utara (Rutter, 2007). Hal ini kerana undang-undang adat menjadi garis panduan utama dalam mengatur cara hidup masyarakat anak negeri dalam menjalankan kehidupan dengan lebih baik mengikut lunas-lunas adat yang betul. Undangundang adat ini menjadi panduan dalam menyelesaikan kes-kes pelanggaran undang-undang adat, hal ehwal perkahwinan, perceraian, hubungan seksual, pengambilan anak angkat dan tuntutan harta pusaka (Native Courts Ordinance, 1953). Undang-undang adat bukan sahaja memberi keadilan kepada seseorang tetapi juga sebagai proses menyelesaikan sesuatu perkara yang menyebabkan terganggunya ketenteraman dan keseimbangan dalam masyarakat agar keseimbangan tersebut dapat dipulihkan semula. Jelas di sini undang-undang adat bertujuan menjamin keamanan dan kesejahteraan individu, masyarakat dan kampung (Sharifah Zaleha Syed Hassan, 1995).

Anak negeri yang melanggar undang-undang adat perlu akur dengan hukuman yang dikenakan mengikut undang-undang adat. Misalnya, adat tuntung (sejenis gendang) yang menjadi amalan tradisi turun dan mempunyai pengaruh yang kuat dalam kehidupan suku kaum Bisaya (Sabah Times, 1980). Tuntung ini berfungsi menyampaikan berita kematian di seluruh kampung dan hanya boleh dimainkan sewaktu berlaku kematian sahaja. Anggota masyarakat yang memainkan tuntung pada masa tidak berlaku kematian akan dikenakan hukuman mengikut undang-undang adat Bisaya menggunakan agung (sejenis gong). Pantang yang terdapat dalam undang-undang adat suku kaum Bisaya ini bertujuan sebagai menghormati orang yang telah mati berkenaan. Perbuatan melanggar pantang semasa berlaku sesuatu kematian dianggap tidak bermoral kerana tidak menghormati orang yang mati dan juga keluarga si mati.

Justeru, setiap hukuman yang dikenakan kepada anak negeri yang melanggar undangundang adat adalah bertujuan mengekang perbuatan tidak bermoral dalam kalangan anggota masyarakat supaya ketenteraman dapat dicapai. Perbuatan yang tidak bermoral adalah seperti zina, mencuri, fitnah, khianat, bergaduh dan sebagainya. Pematuhan kepada undang-undang adat akan menyebabkan keadaan "sejuk" dan mengelakkan keadaan "panas" akibat kemarahan semangat ghaib. Pengamalan undang-undang adat sebagai panduan hidup dalam kalangan anak negeri di Borneo Utara adalah bagi mendisiplinkan anak negeri agar menjaga tata susila dan menjalani kehidupan mengikut undang-undang adat mereka. Menerusi cara tersebut, anak negeri akan terus hidup aman damai dan bermoral. Oleh itu, penubuhan Mahkamah Anak Negeri membolehkan sistem peraturan adat dikekalkan dan dipantau oleh pemimpin anak negeri (Azlizan Mat Enh \& Siti Alwaliyah Mansor, 2017).

Selain itu, pengaruh undang-undang adat anak negeri ini dilihat penting kepada penubuhan Mahkamah Anak Negeri di Borneo Utara kerana faktor pemimpin-pemimpin tempatan lebih mudah menguruskan hal ehwal masyarakat. Dalam proses mengukuhkan dan 
memastikan undang-undang adat anak negeri Borneo Utara terjaga, Mahkamah Anak Negeri ditadbir oleh Ketua Anak Negeri dan Orang Tua yang mahir dengan undang-undang adat (North Borneo Herald, 1884). Pemimpin-pemimpin ini mengamalkan budaya dan adat yang sama serta hidup dalam komuniti yang sama dengan anak negeri. Justeru sebagai pemimpin, mereka mempunyai tanggungjawab dan peranan penting dalam memastikan undang-undang adat suku kaum mereka terpelihara. Ini kerana undang-undang adat berbeza dengan undangundang British jika diadili di Mahkamah Sivil. Misalnya, mengikut undang-undang adat anak negeri di Borneo Utara, bagi kesalahan sumbang mahram akan dikenakan hukuman sogit atau denda yang dibayar dengan binatang ternakan.

Selain itu, penubuhan Majlis Kampung juga merupakan satu bukti undang-undang adat mempunyai pengaruh dalam kehidupan anak negeri Borneo Utara. Majlis Kampung berperanan mentadbir keadilan dalam kampung dan menguatkuasakan undang-undang adat dalam kalangan anak negeri (Sabihah Osman, 1985). Kes-kes anak negeri yang tidak dapat diselesaikan oleh Orang Tua akan dibawa kepada Majlis Kampung untuk dibicarakan. Umpamanya, jika terdapat anggota masyarakat dalam kampung yang telah melakukan kesalahan melanggar undang-undang adat yang berat seperti membunuh, mencuri, merosakkan harta benda orang lain, melarikan isteri orang dan berzina pesalah akan dihadapkan ke Majlis Kampung untuk dihakimi oleh beberapa Orang Tua kampung (Sharifah Zaleha Syed Hassan, 1995). Pengadilan sesuatu kes yang dibuat dalam Majlis Kampung adalah berdasarkan keputusan sebulat suara ataupun undian majoriti ahli-ahli majlis. Walaupun Majlis Kampung hanya berfungsi dalam kampung sahaja, namun mempunyai persamaan seperti Mahkamah Anak Negeri dari segi fungsi dalam mengendalikan hal ehwal anak negeri Borneo Utara berlandaskan undang-undang adat. Justeru, BNBCC melihat keperluan sebuah mahkamah yang khusus untuk mengendalikan hal ehwal anak negeri berlandaskan kepada undang-undang adat kerana tidak sesuai untuk dikendalikan di Mahkamah Sivil British. BNBCC telah membuat reformasi undang-undang adat di Borneo Utara dengan menaiktaraf dan memformalisasikan kedudukan Majlis Kampung kepada Mahkamah Anak Negeri (Sharifah Zaleha Syed Hassan, 1995).

\section{Menjimatkan kos pentadbiran BNBCC}

Semasa BNBCC mentadbir Borneo Utara (1881-1941), BNBCC telah mewujudkan sistem pentadbiran yang bermatlamat untuk menjaga kepentingan dan kedudukan kewangan mereka di negeri ini. BNBCC berusaha untuk menjaga keamanan dan juga kestabilan anak negeri bagi memudahkan mereka mencapai matlamat untuk mengeksploitasi ekonomi di Borneo Utara. Walau bagaimanapun, pada peringkat awal pentadbirannya di Borneo Utara, kedudukan kewangan BNBCC agak lemah (Sabihah Osman, 1985). Ini disebabkan BNBCC perlu mengeluarkan kewangan yang tinggi untuk membayar wang pajakan tahunan Borneo Utara kepada Kesultanan Brunei, Kesultanan Sulu dan Pangiran Temenggong (menteri Brunei). Berikut merupakan jumlah bayaran tahunan Borneo Utara yang perlu dibayar oleh BNBCC.

Berdasarkan jadual 1, Kerajaan BNBCC terpaksa membayar wang pajakan tahunan yang tinggi bagi wilayah Borneo Utara kepada Sultan Brunei, Sultan Sulu dan Pangiran Temenggong iaitu sebanyak $\$ 20,000$ setahun (NBCA 1435). Dalam masa yang sama, BNBCC juga menghadapi masalah kewangan yang tidak kukuh kerana dibebani oleh hutang yang tinggi (The Singapore Free Press and Mercantile Advertiser (1884-1942), 1936). Justeru, bagi mengurangkan hutang dan menstabilkan kewangan kerajaan, BNBCC mentadbir Borneo Utara dengan kos yang paling minimum. Salah satu usaha BNBCC bagi menjimatkan kos pentadbiran kerajaan ialah melalui pelaksanaan sistem pentadbiran secara tidak langsung terhadap anak negeri di Borneo Utara (NBCA 735). 
Jadual 1. Jumlah bayaran tahunan Borneo Utara

\begin{tabular}{lll}
\hline Bayaran & Kawasan & Jumlah \\
\hline Sultan Brunei & $\begin{array}{l}\text { a) Gaya dan Papar } \\
\text { b) Tuaran, Kota Belud, Kudat, Banguey } \\
\text { dan lain-lain Pulau. }\end{array}$ & $\$ 6000$ \\
& $\begin{array}{l}\text { c) Paitan, Sugut, Labuk, Sandakan, } \\
\text { Kinabatangan, Semporna, Tawau }\end{array}$ & $\$ 2000$ \\
& $\begin{array}{l}\text { Pandasan ke Sibuku } \\
\text { Sultan Sulu }\end{array}$ & $\$ 5000$ \\
Pangiran Temenggong & Kimanis dan Benoni & $\$ 3000$ \\
\hline
\end{tabular}

Sumber: Kinabalu Magazine, 1953

Melalui sistem pentadbiran tidak langsung, BNBCC membentuk semula pentadbiran politik dan perundangan anak negeri di Borneo Utara. Ketua Anak Negeri dan Orang Tua diserapkan sebagai jawatan yang paling rendah dalam sistem pentadbiran BNBCC dan menggunakan Mahkamah Anak Negeri sebagai institusi kehakiman yang bertanggungjawab menyelesaikan permasalahan anak negeri Borneo Utara berlandaskan undang-undang adat (C.J. 54/35). Bidang kuasa Mahkamah Anak Negeri adalah kes-kes pelanggaran undangundang adat, perkahwinan, perceraian, pengambilan anak angkat, tuntutan harta pusaka, menjatuhkan hukuman sogit, pengiktirafan taraf anak negeri Sabah. Langkah ini membantu BNBCC menjimatkan kos pentadbiran kerajaan di Borneo Utara. Penggunaan institusi tempatan seperti Ketua Anak Negeri, Orang Tua dan Mahkamah Anak Negeri kerana kedudukan kewangan BNBCC yang tidak kukuh bagi menampung kakitangan kerajaan yang ramai. Oleh yang demikian, melalui sistem pentadbiran secara tidak langsung ini, beberapa orang Ketua Anak Negeri dipertanggungjawabkan untuk menjaga kawasan pentadbiran yang luas (Sabihah Osman, 1985).

Selain itu, kedudukan kewangan yang lemah menyebabkan BNBCC lebih banyak bergantung kepada Ketua Anak Negeri, Orang tua dan Mahkamah Anak Negeri bagi menjamin kestabilan pentadbiran ke atas anak negeri Borneo Utara terutamanya di bahagian pedalaman (Sabihah Osman, 1985). Sehubungan itu, BNBCC menggunakan institusi tempatan berkenaan sepenuhnya bagi mengurangkan kos pentadbiran kerajaan. Buktinya, Ketua Anak Negeri dan Orang Tua diberikan tanggungjawab yang berat kerana mempunyai tanggungjawab dalam hal ehwal pentadbiran, ekonomi dan juga perundangan melibatkan anak negeri (NBCA 735). Atas perintah bertulis daripada Pegawai Daerah, Orang Tua bertanggungjawab mengumpul dan memberi bekalan makanan mahupun pengangkutan kepada pegawai-pegawai kerajaan (The Straits Times, 1903).

Di samping itu, Ketua Anak Negeri dan Orang Tua juga diamanahkan untuk mengutip cukai daripada anak negeri di daerah dan kampung masing-masing (The British North Borneo Herald, 1891). Malahan, Orang Tua juga bertanggungjawab menyediakan tenaga buruh bagi melaksanakan kerja-kerja yang diarahkan oleh pegawai kerajaan seperti mengusahakan ladang, membuat tuak daripada kelapa, membaiki jalan dan kerja-kerja umum lain (The Straits Times, 1903). Sementara dalam aspek perundangan, Ketua Anak Negeri dan Orang Tua ditugaskan sebagai hakim dalam Mahkamah Anak Negeri bagi menyelesaikan permasalahan anak negeri mengikut undang-undang adat dan agama di kawasan masingmasing (NBCA 453).

Seterusnya, dalam usaha mengurangkan kos pentadbiran kerajaan, BNBCC membahagikan Ketua Anak Negeri dan Orang Tua kepada dua kategori iaitu ketua-ketua yang diiktiraf atau ketua tidak diiktiraf daripada kerajaan (NBCA 735). Ketua-ketua yang diiktiraf kerajaan menerima gelaran Ketua Anak Negeri (Native Chief) dan mereka dibahagikan kepada dua kategori iaitu ketua yang mendapat elaun atau tidak mendapat elaun (Sabihah Osman, 1985). Ketua yang mendapat elaun bulanan bertanggungjawab menjaga keamanan, memungut cukai dan menguruskan hal-ehwal keadilan anak negeri di daerah 
mereka. Elaun bulanan yang diterima kira-kira $\$ 5-\$ 40$ sebulan dan sedikit elaun tambahan diberikan bagi tugas menjadi pengadil anak negeri (Sabihah Osman, 1985). Sementara bagi ketua yang tidak mendapat elaun bertanggungjawab memungut cukai dan mendapat $1 / 3$ hasil pungutan cukai sekiranya cukai tersebut diserahkan terus kepada Pegawai Daerah dan hanya 1/10 sahaja yang mereka perolehi sekiranya cukai tersebut diserahkan melalui ketua yang mendapat elaun (The British North Borneo Herald, 1886).

Pembahagian kategori ini membantu BNBCC mengurangkan kos pembayaran elaun kepada Ketua Anak Negeri dan usaha ini seiring dengan objektif kerajaan menjimatkan kos pentadbiran kerajaan. Walaupun diberikan tugas yang berat namun gaji yang diberikan kepada Ketua Anak Negeri dan Orang Tua adalah sedikit dan tidak setimpal dengan bebanan kerja mereka. Pada tahun 1916, daripada 150 orang ketua, kira-kira 60 orang daripadanya hanya mendapat elaun bulanan \$5 sebulan (Ranjit Singh, 2000). Sedangkan gaji sepatutnya yang layak diterima oleh para pemimpin tempatan ini adalah sebanyak $\$ 40$. Dalam hal ini, BNBCC yang sepatutnya membayar gaji para Ketua Anak Negeri sebanyak \$73,000 setahun hanya perlu mengeluarkan duit sebanyak kira-kira $\$ 46,600$ setahun. Justeru, BNBCC dapat menjimatkan sejumlah $\$ 25,000$ duit setahun dalam membayar gaji para pemimpin tempatan ini.

Sekiranya dibandingkan dengan kos penggajian pegawai Mahkamah Anak Negeri dan pegawai Mahkamah Sivil, kos untuk menggajikan pegawai Mahkamah Sivil lebih tinggi berbanding dengan gaji pegawai Mahkamah Anak Negeri. Contohnya, gaji bagi Pegawai Daerah yang bertindak sebagai Magistret kelas 2 sahaja mencecah $\$ 400$ sebulan (NBCA 735). Ini bermakna, gaji bagi seorang Pegawai Daerah dalam setahun adalah sebanyak $\$ 4,800$ setahun. Malahan, gaji bagi pegawai Eropah bagi jawatan paling rendah pun mendapat gaji yang lumayan iaitu sebanyak \$225 sebulan dan \$2,700 setahun (NBCA 735). Sekiranya BNBCC menggaji pegawai Eropah dalam Mahkamah Sivil sebanyak 150 orang di seluruh Borneo Utara, BNBCC terpaksa membelanjakan sebanyak $\$ 405,000$ setahun. Jumlah ini terlalu tinggi dan akan merugikan ekonomi BNBCC. Justeru, penubuhan Mahkamah Anak Negeri dilihat sebagai langkah terbaik bagi dasar menjimatkan kos pentadbiran BNBCC di Borneo Utara.

Selanjutnya bagi tujuan menjimatkan kos pentadbiran, BNBCC melantik sedikit sahaja kakitangan Mahkamah Anak Negeri (NBCA 73E). Kakitangan yang ramai akan menyebabkan BNBCC terpaksa mengeluarkan kos yang tinggi untuk membayar gaji kakitangan mahkamah. Umpamanya, BNBCC hanya melantik seramai 12 orang Ketua Anak Negeri untuk mentadbir Mahkamah Anak Negeri Padas Klias. Namun kawasan yang termasuk dalam bidang kuasa mahkamah ini adalah luas termasuk kawasan Padas Klias dan kawasan sekitarnya seperti Membakut dan Kwala Lama (The British North Borneo Herald, 1886). Malahan, semasa mesyuarat Majlis Penasihat Ketua-Ketua Anak Negeri 1941, KetuaKetua Anak Negeri memohon kerajaan agar mengiktiraf semua Imam dan mencadangkan agar seorang Ketua Imam di Borneo Utara dilantik (NBCA 73E). Walau bagaimanapun, Kerajaan BNBCC menolak permintaan untuk mengiktiraf semua Imam berdasarkan pembayaran bulanan dan Ketua Imam Borneo Utara yang bergaji. BNBCC menolak cadangan berkenaan kerana ia akan menambahkan lagi kos pentadbiran BNBCC ekoran lebih ramai kakitangan Mahkamah Anak Negeri akan dilantik dan dibayar gaji (NBCA 73E).

Oleh yang demikian, jelas bahawa Mahkamah Anak Negeri di Borneo Utara ditubuhkan disebabkan matlamat BNBCC untuk menjimatkan kos pentadbiran kerajaan di negeri ini. Melalui penubuhan Mahkamah Anak Negeri, BNBCC tidak perlu melantik lebih ramai pegawai dalam mengendalikan undang-undang adat anak negeri. BNBCC juga menyerap pemimpin tempatan dalam mengendalikan sepenuhnya pentadbiran Mahkamah Anak Negeri. Manakala dari segi pembayaran gaji juga dapat dijimatkan melalui jumlah gaji yang sedikit kepada Ketua Anak Negeri dan Orang Tua. Justeru, penubuhan Mahkamah Anak 
Negeri di Borneo Utara dilihat sebagai salah satu faktor yang perlu diteruskan demi keuntungan BNBCC.

\section{Piagam Diraja 1881}

Piagam Diraja 1881 (Royal Charter 1881) juga merupakan faktor penting yang menyumbang kepada penubuhan Mahkamah Anak Negeri di Borneo Utara. Sejarah perundangan anak negeri di Borneo Utara bermula apabila Kerajaan British di London menganugerahkan Piagam Diraja kepada BNBCC pada 1 November 1881 (Straits Times Weekly Issue, 1889). Piagam Diraja telah memperuntukkan beberapa fasal yang bertujuan untuk menjaga kepentingan dan hak-hak anak negeri di Borneo Utara (Handbook of North Borneo, 1886). Piagam Diraja melarang BNBCC masuk campur dalam hal ehwal agama dan adat resam anak negeri di Borneo Utara (Straits Times Weekly Issue, 1889). Buktinya, Fasal 8 dalam Piagam Diraja menegaskan bahawa BNBCC mahupun pegawainya tidak boleh sama sekali menganggu agama mana-mana bangsa atau suku kaum anak negeri di Borneo Utara (NBCA 4). Maka, BNBCC perlu patuh dengan perjanjiannya dengan Kerajaan British agar menghormati pegangan agama setiap suku kaum anak negeri negeri di Borneo Utara. Begitu juga dalam Fasal 9 Piagam Diraja yang memperuntukkan (NBCA 4):

"In the administration of justice by the Company to the people of Borneo, or to any of the inhabitants thereof, careful regard shall always be had to the customs and laws of the class or tribes or nation to which the parties respectively belong, especially with respect to the holding possession transfer and disposition of lands and goods, and testate or intestate succession thereto, and marriage, divorce, and legitimacy, and other rights of property and personal rights.

Oleh yang demikian, BNBCC tidak memberi sekatan kepada anak negeri di Borneo Utara ini dalam mengamalkan undang-undang adat mereka berdasarkan suku kaum masingmasing. Perjanjian melalui Piagam Diraja pada tahun 1881 ini menyebabkan BNBCC terikat untuk memberikan pengiktirafan kepada undang-undang adat anak negeri yang menjadi garis panduan dalam mengawal kehidupan masyarakat di Borneo Utara (NBCA 4). Justeru, Piagam Diraja telah menjadi satu langkah Kerajaan British dalam memberikan perlindungan dan kebebasan kepada anak negeri di Borneo Utara dengan mengiktiraf undang-undang adat mereka (NBCA 4). BNBCC telah dipertanggungjawabkan untuk menjaga kebajikan anak negeri Borneo Utara. Menurut Neill Malcolm, Presiden BNBCC, “...our first duty as a Sovereign Power is to safeguard the welfare of the native population"(The Singapore Free Press and Mercantile Advertiser (1884-1942), 1936). Oleh kerana Piagam Diraja menegah BNBCC mencampuri undang-undang adat dan agama yang diamalkan oleh anak negeri, maka sistem keadilan yang ideal bagi anak negeri di Borneo Utara adalah menerusi Mahkamah Anak Negeri. Hanya Mahkamah Anak Negeri sahaja yang benar-benar sesuai untuk mengadili hal ehwal anak negeri di Borneo Utara berdasarkan undang-undang adat mengikut suku kaum. Sementara Mahkamah Sivil pula tidak sesuai untuk menyelesaikan keskes anak negeri berlandaskan undang-undang adat kerana mahkamah ini menggunakan undang-undang Barat. Maka, penubuhan Mahkamah Anak Negeri disifatkan suatu keperluan yang perlu dipenuhi oleh BNBCC agar undang-undang adat anak negeri yang terdiri daripada pelbagai suku kaum di Borneo Utara tidak terganggu. 


\section{Mengelakkan Penentangan Penduduk Tempatan}

Selain itu, penubuhan Mahkamah Anak Negeri di Borneo Utara juga bertujuan untuk mengelakkan penentangan daripada penduduk tempatan terhadap BNBCC. BNBCC bimbang penduduk tempatan menentang pentadbiran kerajaan dan menjangkakan bahawa mereka bakal menghadapi rintangan terutamanya daripada pemimpin Islam di Borneo Utara (Abu Bakar Hamzah, 1991). Masyarakat Islam telah berabad-abad lamanya menerima pengaruh Islam semenjak pemerintahan Kesultanan Brunei dan Kesultanan Sulu di samping mereka amat sensitif dalam hal-hal berkaitan dengan agama Islam dan adat resam mereka (Abu Bakar Hamzah, 1991). Begitu juga halnya dengan komuniti anak negeri yang mempunyai pegangan kuat terhadap adat istiadat mereka. Campur tangan dalam hal ehwal undangundang adat anak negeri boleh membawa kepada penentangan masyarakat yang sukar menerima perubahan baru dalam sistem amalan dan kepercayaan mereka. Beberapa penentangan daripada penduduk tempatan kepada kerajaan BNBCC pada awal pentadbirannya di Borneo Utara telah menjadi pengajaran kepada kuasa penjajah ini agar tidak membuat sebarang dasar yang boleh membangkitkan kemarahan penduduk tempatan.

Contohnya, penentangan Mat Salleh terhadap Kerajaan British pada tahun 1894 (North Borneo Police Magazine, 1957). BNBCC telah melarang Mat Salleh mengutip cukai di Sungai Sungut kerana Mat Salleh tidak mempunyai hak ke atas kawasan ini lagi setelah Sultan Sulu telah memberikan wilayahnya di Borneo Utara kepada BNBCC (Siti Aidah Hj. Lokin, 2007). Sementara Mat Salleh bertegas bahawa beliau tetap mempunyai kuasa penuh untuk mengutip cukai di Sungai Sugut kerana kawasan ini telah diserahkan kepadanya oleh Sultan Sulu dan dalam sistem pentadbiran Kesultanan Sulu, sultan tidak boleh menyerahkan wilayah yang dimiliki oleh para pembesar kepada pihak lain tanpa mendapat persetujuan daripada pemilik wilayah berkenaan. Mat Salleh juga turut membantah pelaksanaan beberapa cukai dan lesen perahu yang dikenakan oleh BNBCC terhadap beliau dan para pengikutnya (Siti Aidah Hj. Lokin, 2007).

BNBCC mengarahkan agar Mat Salleh ditangkap kerana kesalahannya mengutip cukai di Sungai Sugut dan tuduhan melindungi pembunuh dua orang Dayak serta beberapa orang yang telah menyamun sebuah kedai di pulau berhampiran dengan bandar Sandakan (Berita Harian, 1961). Sehubungan itu, bermula penentangan Mat Salleh terhadap BNBCC. Serangan Mat Salleh ke atas BNBCC di Pulau Gaya telah menyebabkan BNBCC mengalami kerugian yang begitu besar. Antara kerugian yang dilaporkan ialah sebanyak 570 buah rumah terbakar, hasil padi bernilai $\$ 20,000$ dan kerugian lain dianggarkan sebanyak $\$ 10,000$ (The Straits Times, 1898). Semua bangunan Kerajaan BNBCC di pulau ini juga dimusnahkan oleh Mat Salleh (North Borneo Herald, 1922).

Selain Mat Salleh, BNBCC juga turut menghadapi penentangan yang besar daripada masyarakat Murut di daerah Rundum yang dikenali sebagai pemberontakan Rundum pada tahun 1915 (Borneo Mail, 1995). Penentangan ini disebabkan masyarakat Murut di kawasan pedalaman khususnya di Rundum dan Pensiangan yang tidak berpuas hati dengan pentadbiran BNBCC yang memperkenalkan pelbagai cukai baru seperti cukai ladang dan cukai minuman-minuman keras seperti tapai dan bahar. Setiap satu gantang $(3 \mathrm{~kg})$ beras akan dikenakan cukai sebanyak 2 sen dan setiap gantang ibu akan dikenakan cukai sebanyak 1 sen serta cukai sebanyak 25 sen dikenakan bagi setiap satu pokok kelapa untuk membuat bahar (Borneo Mail, 1995).

Malahan, masyarakat Murut juga dilarang membuka hutan untuk tanaman melainkan telah mendapat permit daripada BNBCC. Sedangkan bagi masyarakat Murut, mereka lebih suka menjalankan kegiatan pertanian pindah yang menjadi kegiatan ekonomi tradisi mereka. Setiap tanah yang dibuka perlu membayar cukai sebanyak 50 sen bagi setiap ekar. Masyarakat Murut ini juga dipaksa oleh BNBCC melakukan kerja-kerja membuat jalan tanpa 
upah (Borneo Mail, 1995). BNBCC telah menghalang kebebasan adat resam masyarakat Murut dengan menghentikan amalan tradisi memenggal kepala musuh (Siti Aidah Hj. Lokin. 2007). Pentadbiran BNBCC yang sama sekali tidak mengambil kira adat istiadat dan cara hidup masyarakat tempatan telah membangkitkan kemarahan masyarakat Murut. Justeru, pelbagai perubahan dalam pentadbiran yang diperkenalkan oleh BNBCC di Borneo Utara telah menggugat adat dan nilai etika masyarakat Murut sehingga membawa kepada Pemberontakan Rundum yang diketuai oleh Antanom. Pemberontakan Rundum dianggap sebagai peperangan untuk menegakkan adat dan kepercayaan mereka yang telah dicabuli oleh BNBCC (Daily Express, 2012). Antanom telah berjaya menyatukan beberapa kumpulan masyarakat Murut untuk menentang BNBCC. Pertempuran antara Antanom dan BNBCC telah mengakibatkan banyak rumah tumpangan, jambatan dan pos telegraf musnah serta wayar telefon sejauh 15 batu di selatan Rundum hilang (Ranjit Singh, 2000).

Secara keseluruhannya, penentangan Mat Salleh dan Pemberontakan Rundum telah memberikan kerugian besar kepada ekonomi BNBCC. Serangan daripada pemberontakanpemberontakan ini telah menyebabkan kemusnahan beberapa kawasan pentadbiran BNBCC. Malahan, BNBCC juga telah mengeluarkan kewangan yang besar dalam usaha membanteras ancaman Mat Salleh dan Antanom melalui beberapa siri penentangan. Penentangan Mat Salleh dan Antanom bukan sahaja memberi kesan buruk kepada kestabilan politik BNBCC, malahan juga memberi kerugian teruk kepada ekonomi mereka di Borneo Utara. Sekiranya kestabilan politik tergugat maka kestabilan ekonomi BNBCC di Borneo Utara juga akan tergugat.

Justeru, penentangan Mat Salleh dan Pemberontakan Rundum ini telah memberi kesedaran dan pengajaran kepada BNBCC agar lebih berhati-hati dalam melaksanakan perubahan pentadbiran di Borneo Utara (Siti Aidah Hj. Lokin, 2007). Perubahan dalam sistem kepercayaan dan adat istiadat mereka boleh mengeruhkan hubungan BNBCC dengan penduduk. Sehubungan itu, BNBCC tidak mahu lagi melakukan perubahan dalam sistem adat dan kepercayaan masyarakat tempatan di Borneo Utara yang boleh membangkitkan kemarahan mereka yang seterusnya membawa penentangan demi penentangan penduduk tempatan kepada BNBCC (Vilkon Tauning \& Novel Lyndon, 2016). Oleh yang demikian, penubuhan Mahkamah Anak Negeri di Borneo Utara merupakan salah satu langkah BNBCC untuk menjaga undang-undang adat dan sistem kepercayaan anak negeri. Melalui penubuhan Mahkamah Anak Negeri, adat dan kepercayaan tradisi anak negeri terjaga dan dihormati. Penubuhan Mahkamah Anak Negeri ini juga mampu mengurangkan ketegangan di antara BNBCC dan masyarakat Borneo Utara kerana Orang Tua dan Ketua Anak Negeri yang berkebolehan diberikan peluang mentadbir sistem keadilan anak negeri. BNBCC menyerahkan tanggungjawab mentadbir undang-undang adat anak negeri sepenuhnya kepada pemimpin anak negeri itu sendiri menerusi Mahkamah Anak Negeri (NBCA 453, 1937).

\section{Pertambahan Populasi Penduduk}

Pertambahan populasi penduduk di Borneo Utara juga telah menjadi salah satu faktor penyumbang kepada penubuhan Mahkamah Anak Negeri di Borneo Utara. Tujuan BNBCC menubuhkan Mahkamah Anak Negeri bagi setiap daerah di negeri ini adalah bagi menampung kes-kes anak negeri Borneo Utara yang melibatkan undang-undang adat suku kaum mereka. Hal ini kerana jumlah penduduk Borneo Utara semakin meningkat setiap tahun.

Berdasarkan jadual 2, jelas menunjukkan bahawa jumlah penduduk di Borneo Utara semakin meningkat saban tahun dari tahun 1891 sehingga tahun 1911. Jumlah penduduk Borneo Utara yang dilaporkan pada tahun 1891 adalah seramai 67,062 orang termasuk kumpulan anak negeri dan kumpulan imigran yang datang ke negeri ini (State of North 
Borneo Census Report, 1921). Pada tahun 1901, berlaku pertambahan penduduk Borneo Utara seramai 37,465 orang menjadikan jumlah keseluruhan penduduk pada tahun tersebut adalah seramai 104,527 orang. Begitu juga pada tahun 1911, jumlah penduduk semakin bertambah seramai 103,656 orang dan mencatatkan jumlah penduduk Borneo Utara yang tinggi iaitu seramai 208,183 orang.

Jadual 2. Jumlah populasi penduduk Borneo Utara tahun 1891-1911

\begin{tabular}{lccc}
\hline & \multicolumn{3}{c}{ Tahun } \\
\cline { 2 - 4 } Kategori Penduduk & $\mathbf{1 8 9 1}$ & $\mathbf{1 9 0 1}$ & $\mathbf{1 9 1 1}$ \\
\hline Dusun & 34,166 & 33,456 & 87,951 \\
Murut & - & 12,230 & 25,314 \\
Bajau & 11,150 & 10,885 & 22,587 \\
Brunei & 3,546 & 6,767 & 6,877 \\
Suluk & 3,733 & 6,373 & 5,303 \\
Orang Sungai & - & 4,784 & 9,168 \\
Lain-lain Kumpulan Anak Negeri & 6,454 & 6,549 & 15,384 \\
Cina & 7,156 & 12,282 & 26,002 \\
Lain-lain Penduduk & 857 & 11,201 & 9,597 \\
Jumlah & 67,062 & 104,527 & 208,183 \\
\hline Sumber: State of North Borneo Census Report 1921; North Borneo Report on the Census of Population \\
Taken on 10th August 1960 by L.W. Jones; Annual Bulletin of Statistics Sabah 1965; British North \\
Borneo Official Gazette, 1 Febuari 1892. \\
\multicolumn{3}{|}{}
\end{tabular}

Jumlah populasi penduduk Borneo Utara bagi kumpulan anak negeri menunjukkan peningkatan bagi tempoh 20 tahun ini. Pada tahun 1891, laporan jumlah populasi bagi suku kaum Dusun adalah digabungkan bersama dengan jumlah populasi bagi suku kaum Murut dan Orang Sungai yang keseluruhannya mencatatkan seramai 34,166 orang (State of North Borneo Census Report, 1921). Namun, laporan jumlah populasi bagi suku kaum Dusun, Murut dan Orang Sungai diasingkan bagi tahun 1901 dan 1911. Kategori bagi kumpulan lainlain anak negeri merujuk kepada suku kaum asli Borneo Utara yang lain seperti Kadayan, Tidong, Tutong, Bisaya dan lain-lain (Annual Bulletin of Statistics Sabah, 1965). Jumlah keseluruhan bagi kumpulan anak negeri Borneo Utara pada tahun 1891 adalah seramai 59,049 orang. Jumlah populasi anak negeri Borneo Utara semakin meningkat pada tahun 1901 iaitu seramai 81,044 orang (Census of North Borneo, 1901). Begitu juga dengan tahun 1911, jumlah populasi anak negeri di Borneo Utara meningkat dua kali ganda daripada tahun sebelumnya iaitu seramai 172,584 orang.

Peningkatan jumlah penduduk di Borneo Utara juga disebabkan oleh dasar BNBCC yang menggalakkan kemasukan imigran daripada negara jiran seperti Indonesia, Filipina, China dan sebagainya ke Borneo Utara bagi memenuhi keperluan tenaga buruh bagi sektor pertanian seperti getah dan tembakau. Malahan, BNBCC membawa imigran dari tanah besar China secara besar-besaran melalui peruntukan pas percuma. Justeru, tidak menghairankan apabila jumlah imigran Cina semakin meningkat dari tahun 1891 sehingga tahun 1911. Kaum Cina yang lahir di Sabah sebelum 1 November 1931 dikategorikan sebagai bumiputera (NBCA 341). Walau bagaimanapun, ramai kaum Cina yang berkahwin dengan anak negeri Sabah dan membentuk suku kaum Sino-Native seperti Sino-Dusun, Sino-Kadazan, SinoBajau dan sebagainya. Terdapat banyak permohonan untuk mendapatkan status anak negeri Sabah daripada anak yang lahir daripada suku kaum ini. Mahkamah Anak Negeri bertanggungjawab mengeluarkan Sijil Anak Negeri sejak tahun 1960-an lagi bagi membolehkan individu yang mempunyai keturunan anak negeri Sabah hasil daripada perkahwinan campur mendapatkan status rasmi sebagai anak negeri Sabah (MSTAR, 2015).

Oleh yang demikian, memandangkan jumlah populasi penduduk Borneo Utara semakin meningkat dengan kadar yang tinggi saban tahun, maka penubuhan Mahkamah 
Anak Negeri menjadi satu keperluan yang perlu dilaksanakan dalam sistem perundangan anak negeri di Borneo Utara. Hal ini kerana BNBCC tidak mampu menampung keperluan dari segi kehakiman kepada penduduk Borneo Utara sama ada bagi kumpulan anak negeri mahupun bukan anak negeri. Sedangkan BNBCC kekurangan pegawai-pegawai Eropah untuk mengendalikan pelbagai kes penduduk Borneo Utara yang semakin tinggi. Pada tahun 1911, BNBCC hanya mempunyai seramai 355 orang pegawai-pegawai Eropah sahaja (State of North Borneo Census Report, 1921). Justeru, bagi mengurangkan beban Mahkamah Sivil, sebarang kes yang melibatkan adat anak negeri akan diserahkan kepada Mahkamah Anak Negeri.

\section{Kesimpulan}

Tuntasnya, Majlis Kampung yang merupakan mahkamah tradisional masyarakat anak negeri sebelum zaman penjajahan mempunyai ciri dan peranan seperti Mahkamah Anak Negeri yang ada pada hari ini. Namun namanya masih lagi dikenali sebagai mahkamah adat. Penghakiman yang dijalankan bagi mengadili komuniti anak negeri Borneo Utara adalah berpandukan kepada undang-undang adat anak negeri mengikut suku kaum masing-masing. Walau bagaimanapun, mereka tidak memiliki rekod undang-undang yang tersendiri dan segala undang-undang adalah didapati secara turun-temurun melalui lisan daripada nenek moyang. Justeru, pemilihan Orang Tua bagi mentadbir penduduk kampung dari aspek pentadbiran dan kehakiman adalah berlandaskan pengalaman, kewibawaan dan pengetahuan yang luas dalam undang-undang adat mereka. Memandangkan pengaruh undang-undang adat amat kuat dalam kalangan komuniti anak negeri di Borneo Utara, maka BNBCC menjadikannya satu faktor untuk menubuhkan Mahkamah Anak Negeri di negeri ini.

Pengiktirafan BNBCC terhadap undang-undang anak negeri adalah berikutan kepada perjanjian yang terdapat Piagam Diraja 1881. Piagam ini mengekang BNBCC daripada mencampuri hal ehwal undang-undang adat anak negeri yang mana membawa kepada penubuhan Mahkamah Anak Negeri di Borneo Utara. Penubuhan Mahkamah Anak Negeri ini menandakan BNBCC mematuhi janjinya untuk menghormati adat istiadat masyarakat anak negeri di Borneo Utara. Pada awal peringkat pentadbiran BNBCC di Borneo Utara pada tahun 1881, BNBCC mengalami beberapa kekangan dalam aspek ekonomi. Justeru, BNBCC memulakan dasar menjimatkan kos pentadbiran di Borneo Utara. Salah satu langkah menjimatkan kos pentadbiran kerajaan adalah melalui penubuhan Mahkamah Anak Negeri. Selain itu, BNBCC mengiktiraf undang-undang adat anak negeri telah mewujudkan keseimbangan dan kesejahteraan dalam kalangan anak negeri sekaligus mengelakkan penentangan daripada penduduk tempatan terhadap BNBCC yang boleh mengancam kestabilan politik dan ekonomi mereka di Borneo Utara. Melalui penubuhan Mahkamah Anak Negeri, kebajikan anak negeri terjaga dalam konteks undang-undang adat.

\section{Rujukan}

Abu Bakar Hamzah. (1991). Development of the Native Chief Institution of Sabah. Borneo Review. 2(2): 178-187.

Annual Bulletin of Statistics Sabah. (1965). Kuala Lumpur: Jabatan Perangkaan Malaysia.

Azlizan Mat Enh, \& Siti Alwaliyah Mansor. (2017).Sistem Perundangan British dan Disiplin Banduan Penjara Pulau Pinang, 1870-1957: Implikasinya ke atas masyarakat. Geografia: Malaysian Journal of Society and Space. 13(1): 73-86.

Berita Harian. (1961). 29 Januari. 
Borneo Mail. (1995). 14 Mei.

C. J. 54/35. Surat Daripada Chief Justice Kepada Government Secretary, 6 September 1935.

Census of North Borneo (1901). Supplement of British North Borneo Official Gazette, 5 Oktober.

Colonial Reports of North Borneo, 1949.

Daily Express. (2012). 22 April.

Ranjit Singh, D.S. (2000). The making of Sabah 1865-1941: The dynamics of indigenous society. Kuala Lumpur: University of Malaya Press.

Handbook of North Borneo.(1886).

Kinabalu Magazine. (1953). Vol. III No. 1. July.

KKT\&P. (S) 100-1/14/(56), 2010

Mosli Tarsat. (2007). Institusi pentadbiran pribumi: Satu kajian mengenai Ketua Anak Negeri di Sabah, 1946-1990. (Tesis Sarjana) Sekolah Sains Sosial, Universiti Malaysia Sabah.

NBCA 4. The Laws of North Borneo Vol. VI. 1954.

NBCA 73E. Native Chief's Advisory Council Meetings, 1941.

NBCA 453. Native Administration Legislation 2, 1937.

NBCA 735. Indirect Rule and the System of Administration of the Natives of North Borneo, 1935.

NBCA 806. Village Administration Ordinance 5, 1913.

NBCA 1435. Sir Alfred Dent Private Correspondence of Alfred \& Edward Dent, 1977-1978.

North Borneo Herald. (1884). Vol. II.

North Borneo Herald. (1922). 1 Ogos.

North Borneo Police Magazine, 1957.

Phelan, P. R. (2003). The Traditional Legal System of Sabah, Kota Kinabalu: Yayasan Sabah Press.

Rutter, O. (2007). The Pagans of North Borneo. Kota Kinabalu: Opus Publications.

Sabah Times. (1980). 22 Oktober.

Sabihah Osman. (1985). Pentadbiran Pribumi Sabah 1881-1941. Bangi: Penerbit Universiti Kebangsaan Malaysia.

Sharifah Zaleha Syed Hassan. (1995). Mahkamah Anak Negeri dan pelanjutan undangundang Adat di Sabah: Satu interprestasi sosiobudaya. Dlm. Ismail Hussein, A. Aziz Deraman, \& Abd. Rahman Al-Ahmadi (pnyt.), Tamadun Melayu (hlm: 1532-1558). Kuala Lumpur: Dewan Bahasa dan Pustaka.

Siti Aidah Hj. Lokin. (2007). Perubahan sosioekonomi dan pentadbiran masyarakat peribumi Sabah (1881-1963). Kota Kinabalu: Penerbit Universiti Malaysia Sabah.

State of North Borneo Census Report. 1921.

Straits Times Weekly Issue. (1889). 7 Jun.

The British North Borneo Herald. (1891). Vol. IX.

The British North Borneo Herald. (1886). Vol. IV - XI.

The Singapore Free Press and Mercantile Advertiser (1884-1942). (1900). 5 Febuari.

The Singapore Free Press and Mercantile Advertiser (1884-1942). (1936). 13 Julai.

The Straits Times. (1898). 14 Mei.

The Straits Times. (1903). 22 September.

Vilkon Tauning, \& Novel Lyndon. (2016). Pandangan etnik Sungai terhadap Gerakan Sabah keluar Malaysia (SSKM): Satu kajian fenomenologi. Geografia: Malaysian Journal of Society and Space. 12(5): 44-52. 